\title{
APLIKASI PERAMALAN KURS BITCOIN-RUPIAH DENGAN MENGGUNAKAN METODE DOUBLE EXPONE NTIAL SMOOTHING
}

\author{
Eva Darnila ${ }^{1}$, Muhammad Fikry ${ }^{2}$, Hizamrul Jaen ${ }^{3}$ \\ Jurusan Teknik Informatika, Fakultas Teknik, Universitas Malikussaleh \\ eva.darnila@unimal.ac.id 1 \\ muh.fikry@unimal.ac.id ${ }^{2}$ \\ hizamrul@gmail.com ${ }^{3}$
}

\begin{abstract}
Abstrak
Abstrak - Perkembangan teknologi meghadirkan banyak inovasi. Salah satu inovasi teknologi adalah berkembangnya Cryptocurrency atau mata uang Kripto. Salah satu jenis Cryptocurrency adalah Bitcoin. Karena beberapa faktor, Bitcoin menjadi terkenal di seluruh dunia, sehingga sering diperdagangkan layaknya perdagangan mata uang pada umumya. Namun karena belum adanya regulasi dari pemerintah, membuat harga bitcoin menjadi tidak terkendali sehingga sering terjadi fluktuasi besar besaran. Metode Double Exponential Smoothing adalah sebuah metode yang sering diguakan dalam kebutuhan Forecastng. Metode ini memanfaatka data historis pada priode tertentu dalam proses prediksi. Untuk metode ini akan diuji dalam sebuah rancangan dan pengembangan system berbasis web, dimana sampel data akan di kalkulasikan dengan Metode Double Exponential Smoothing. Penelitian ini menguji sekitar 5 data setiap harinya selama 10 hari, dengan parameter $a$ (alpha) 0.4035. menghasilkan tingkat akurasi senilai 70\%. Hasil peramalan itu akan di sajikan dalam bentuk tabel dan grafik.
\end{abstract}

Kata Kunci : bitcoin, forecasting, double exponential smoothing, kurs, cryptocurrency

\section{Pendahuluan}

Beberapa tahun terakhir ini, mata uang digital mengalami perkembangan yang begitu pesat dikarenakan kebutuhan 
masyarakat akan bertransaksi meningkat pesat. Hal ini membuat berbagai macam inovasi bermunculan dalam metode bertransaksi secara online. Salah satu metode yang saat ini sedang popular di dunia digital adalah bertransaksi dengan menggunakan mata uang kripto, atau Cryptocurrency. Mata uang ini banyak macam nya dengan berbagai macam keunggulan yang ditawarkan. Bitcoin adalah salah satu jenis Cryptocurrency yang paling popular saat ini. Bitcoin adalah Cryptocurrency pertama di dunia yang dikenalkan oleh Sathoshi Nakamoto di tahun 2008.

Bitcoin kemudian berkembang pesat dari waktu ke waktu dimana bitcoin digunakan sebagai alat bertransaksi secara online. Bitcoin memliki sifat seperti mata uang konvensional yang kita kenal seperti Rupiah, Dollar, atau Euro. Bitcoin juga memiliki nilai tukar ke mata uang konvensional. Namun harga bitcoin menjadi tidak terkendali dikarenakan belum ada Lembaga yang secara resmi mengatur peredaran Bitcoin. Akibatnya harga bitcoin menjadi tidak terkendali sehingga menghasilkan fluktuasi harga secara besar besaran. Sebagai contoh, Saat penelitiah ini dilakukan (Bulan Februari 2018), nilai kurs Bitcoin berada di level Rp. 136,4 juta Rupiah per satu Bitcoin nya. Padahal, pada bulan 12 tahun 2017 harga Bitcoin menyentuh nilai Rp. 250 juta per satu Bitcoin nya. Padahal pada awal tahun 2011 Bitcoin, hanya mempunyai nilai \$1 saja atau sekitar Rp.13,500 kurs maret 2018 (Data dari CoinGecko Company, 2018).

Investasi Bitcoin adalah hal yang banyak menyita perhatian masyarakat. Harga Bitcoin yang tak menentuk dan fluktuatif mempunyai nilai tantangan sendiri bagi para investornya. Para investor mendapatkan keuntungan dari selisih harga Bitcoin terhadap rupiah dari waktu ke waktu. Para investor membeli harga bitocin saat harga nilai tukarnya murah dan menjualnya saat kurs nilai tukarnya naik, hal ini disebut dengan Foreign Exchage (Forex). Selisih naik- turunnya harga yang begitu jauh hingga menyentuh puluhan juta rupiah dalam waktu yang singkat menjadikan investasi Bitcoin sangat beresiko. Dibutuhkan persiapan strategi dan perhitungan yang matang dalam menginvestasikan asset yang dimiliki ke Bitcoin.

Dari permasalahan diatas, penulis menawarkan solusi yaitu dengan meramal harga Bitcoin menggunakan perhitungan 
matematis yang menghitung pola pergerakan Bitcoin berdasarkan data historis pergerakan Bitcoin dimasa sebelumnya. Dengan adanya perangkat lunak ini, diharapkan bisa menghasilkan output berupa angka harga Bitcoin di masa mendatang sehingga menjadi salah satu elemen pendukung keputusan dalam pengguna Bitcoin khususnya para investor sebelum memutuskan untuk berinvestasi mata uang Bitcoin. Sehingga memungkinkan mengurangi resiko kerugian.

Pada penelitian ini, penulis memilih metode Double Exponential Smoothing sebagai metode yang akan diuji dalam penelitian ini. Double Exponential Smoothing merupakan salah satu metode yang sering digunakan dalam bidang statistik untuk keperluan peramalan. Metode ini menggunakan nilai parameter yang diapat dari perhitungan secara Trial and Error untuk menghasilkan nilai paling akurat. Metode ini lebih tepat digunakan untuk peramalan trend kenaikan suatu nilai.(Annastasya Liberty dan Radiant V. Imbar, 2015)

\section{Metode Penelitian}

Penelitian ini dilakukan mulai dari 25 Februari 2018 hingga selesai. Lokasi penelitian ini dilakukan di kota Lhokseumawe. Data yang dikumpulkan yaitu berupa data historis Kurs Bitcoin Rupiah dalam Priode tertentu. Data historis akan diambil sebanyak 10 sampel dalam satu priode. Jadi, satu priode berisi 10 sampel data yang nantinya akan di kalkulasi menggunakan metode Double Exponential Smoothing.

Data yang bersumber dari API Bitcoin INDODAX, sebuah perusahaan trading Bitcoin - Rupiah. Data tersebut merupakan data Kurs Bitcoin - Rupiah terbaru.

\section{Hasil dan Pembahasan}

Pada penelitian ini, penulis akan menguji metode Double Exponential Smoothing atau disingkat D.E.S untuk memprediksi pergerakan Kurs Bitcoin-Rupiah dalam priode satu hari. Metode ini akan mengkalkulasikan sampel data harga Bitcoin hari ini dengan mengan parameter metode untuk mendapatkan prediksi harga besok harinya. Sampel data diambil secara acak sebanyak 
sepuluh sampel harga. Penulis akan mengambil data data dari tahun sebelumnya untuk melihat performa dari metode ini yang diukur dari tingkat akurasi keberhasilannya.

\section{A. Deskripsi Sistem}

Pada nantinya, sistem ini akan memproses input berupa sampel data dari harga Bitcoin dalam sebuah priode tertentu, sampel setiap satu priodenya adalah 10 sampel. Sampel tersibut akan diproses menggunakan metode Double Exponential Smoothing yang akan menghasilkan presiksi harga Bitcoin keesokan harinya. Dalam proses ini, keakuratan akurasi bisa beragam dikarenakan metode ini menggunakan dua parameter yang akan menentukan hasil peramalan, juga menentukan akurasi dari peramalan tersebut. Dan parameter tersebut juga di tentukan secara acak, dengan Trial and Error untuk menghasilkan parameter terbaik yang bisa menghasilkan tingkat akurasi terbaik.

Setelah menghasilkan output, sistem tersebut akan menyajikan data tersebut dalam bentuk tabel dan grafik yang dimana akan menjelaskan pergerakan harga Bitcoin dan pergerakan prediksi harga. Grafik ini akan membantu investor karena pergerakan data ditampilkan secara visual sehingga lebih mudah di mengerti.

\section{B. Perhitungan Manual Double Eksponential Smoothing}

Pada perhitungan manual ini, penulis menggunakan beberapa data harga Bitcoin. Bisa kita lihat pada tabel dibawah ini : 
Tabel 1. Sampel Harga

\begin{tabular}{|c|c|c|c|c|c|}
\hline \multirow{2}{*}{ TGL } & \multicolumn{5}{|c|}{ Sampel } \\
\cline { 2 - 6 } & $\mathbf{1}$ & $\mathbf{2}$ & $\mathbf{3}$ & $\mathbf{4}$ & $\mathbf{5}$ \\
\cline { 2 - 6 } & & & & & \\
\hline & $R p$ & $R p$ & $R p$ & $R p$ & $R p$ \\
$01 / 06 / 2015$ & 2.952 .204 & 2.961 .992 & 2.989 .381 & 2.989 .672 & 2.968 .998 \\
\hline & $R p$ & $R p$ & $R p$ & $R p$ & $R p$ \\
$02 / 06 / 2015$ & 2.980 .469 & 2.990 .257 & 2.992 .394 & 2.992 .685 & 2.972 .011 \\
\hline & $R p$ & $R p$ & $R p$ & $R p$ & $R p$ \\
$03 / 06 / 2015$ & 2.983 .482 & 2.993 .270 & 2.981 .200 & 2.981 .491 & 2.960 .817 \\
\hline & $R p$ & $R p$ & $R p$ & $R p$ & $R p$ \\
$04 / 06 / 2015$ & 2.972 .288 & 2.982 .076 & 3.002 .708 & 3.002 .999 & 2.982 .325 \\
\hline & $R p$ & $R p$ & $R p$ & $R p$ & $R p$ \\
$05 / 06 / 2015$ & 2.993 .796 & 3.003 .584 & 3.014 .006 & 3.014 .297 & 2.993 .623 \\
\hline
\end{tabular}

Dengan parameter yang digunakan :

Alpha: 0.4035

Beta : $1-0,4035=0,5965$

Hal yang pertama dilakukan adalah Smoothing pertama, kemudian smoothing kedua, penentuan konstanta, slope, dan hasil peramalan ini, untuk mempersingkat pembahasan, kita dapat mengambil data Kurs Bitcoin-Rupiah pada tanggal 1 Juni 2015 yang nantinya akan menghasilkan prediksi harga Kurs Bitcoin-Rupiah untuk esok harinya yaitu tanggal 2 Juni 2015.

1. Smoothing Pertama

$$
\begin{gathered}
S t=a \cdot X t+(1-a) \boldsymbol{S}^{\prime} \boldsymbol{t}-\mathbf{1} \\
S^{\prime} 1=(0.4035) R p \cdot 2,952,204=R p \cdot 2,952,204 \\
S^{\prime} 2=(0.4035) R p \cdot 2,961,992+(0,5965) R p \cdot 2,952,204 \\
=R p \cdot 2,956,183 \\
S^{\prime} 3=(0.4035) R p \cdot 2,989,381+(0,5965) R p \cdot 2,956,183 \\
=R p \cdot 2,969,678 \\
S^{\prime} 4=(0.4035) R p \cdot 2,989,672+(0,5965) R p \cdot 2,969,678 \\
=R p \cdot 2,977,805
\end{gathered}
$$




$$
\begin{gathered}
S^{\prime} 5=(0.4035) R p \cdot 2,968,998+(0,5965) R p \cdot 2,977,805 \\
=R p \cdot 2,974,225
\end{gathered}
$$

2. Smoothing Kedua

$$
\begin{gathered}
S t=a S^{\prime} t+(1-a) S^{\prime \prime} t-1 \\
S^{\prime \prime} 1=(0.4035) R p \cdot 2,952,204=R p \cdot 2,952,204 \\
S^{\prime \prime} 2=(0.4035) R p \cdot 2,956,183+(0,5965) R p \cdot 2,952,204 \\
=R p \cdot 2,953,821 \\
S^{\prime \prime} 3=(0.4035) R p \cdot 2,969,678+(0,5965) R p \cdot 2,956,183 \\
=R p \cdot 2,961,669 \\
S^{\prime \prime} 4=(0.4035) R p \cdot 2,977,805+(0,5965) R p \cdot 2,969,678 \\
=R p \cdot 2,972,982 \\
S^{\prime \prime} 5=(0.4035) R p \cdot 2,974,225+(0,5965) R p \cdot 2,977,805 \\
=R p \cdot 2,976,350
\end{gathered}
$$

3. Konstanta (at)

$$
\begin{gathered}
\boldsymbol{a t}=\mathbf{2} * \boldsymbol{S}^{\prime} \boldsymbol{t}-\boldsymbol{S}^{\prime \prime} \boldsymbol{t} \\
\mathrm{A} 1=(2 * R p \cdot 2,952,204)-R p \cdot 2,952,204=R p \cdot 2,952,204 \\
\mathrm{~A} 2=(2 * R p \cdot 2,956,183)-R p \cdot 2,953,821=R p \cdot 2,958,554 \\
\text { A3 }=(2 * R p \cdot 2,969,678)-R p \cdot 2,961,669=R p \cdot 2,977,687 \\
\text { A4 }=(2 * R p \cdot 2,977,805)-R p \cdot 2,972,982=R p \cdot 2,982,629 \\
\text { A5 }=(2 * R p \cdot 2,974,225)-R p \cdot 2,976,350=R p \cdot 2,972,100
\end{gathered}
$$

4. Slope (bt)

$$
\begin{gathered}
\boldsymbol{b} \boldsymbol{t}=\frac{\boldsymbol{a}}{\mathbf{1}-\boldsymbol{a}}\left(\boldsymbol{S}^{\prime} \boldsymbol{t}-\boldsymbol{S}^{\prime \prime} \boldsymbol{t}\right) \\
\mathrm{B} 1=\frac{0,4035}{0,5965} *(R p \cdot 2,952,204-R p \cdot 2,952,204)=0 \\
\mathrm{~B} 2=\frac{0,4035}{0,5965} *(R p \cdot 2,956,119-R p \cdot 2,953,770)=R p \cdot 1,617 \\
\text { B3 }=\frac{0,4035}{0,5965} *(R p \cdot 2,969,424-R p \cdot 2,960,032)=R p \cdot 5,486 \\
\text { B4 }=\frac{0,4035}{0,5965} *(R p \cdot 2,977,523-R p \cdot 2,967,028)=R p \cdot 3,304 \\
\mathrm{~B} 5=\frac{0,4035}{0,5965} *(R p \cdot 2,974,113-R p \cdot 2,969,862)=R p-1455
\end{gathered}
$$


5. Forecast (Hasil Peramalan)

$$
\begin{aligned}
& \mathrm{St}=\mathrm{at}+\mathrm{bt}, \\
& \mathrm{St}=\mathrm{a} 5+\mathrm{b} 5
\end{aligned}
$$

6. Hasil Peramalan

\begin{tabular}{|c|c|c|c|c|c|c|}
\hline Tanggal & $\begin{array}{c}\text { Sampel } \\
\text { Data }\end{array}$ & Forecast & Selisih & Status & Prediksi & $\begin{array}{c}\text { Hasil } \\
\text { Peramalan }\end{array}$ \\
\hline $01 / 06 / 2015$ & $\begin{array}{c}\mathrm{Rp} \\
2.952 .204\end{array}$ & $\begin{array}{c}\mathrm{Rp} \\
2.970 .645\end{array}$ & $\begin{array}{c}\text {-Rp. } \\
18.441\end{array}$ & NAIK & NAIK & BERHASIL \\
\hline $02 / 06 / 2015$ & $\begin{array}{c}\mathrm{Rp} \\
2.980 .469\end{array}$ & $\begin{array}{c}\mathrm{Rp} \\
2.984 .387\end{array}$ & $\begin{array}{c}-\mathrm{Rp} \\
3.918\end{array}$ & NAIK & NAIK & BERHASIL \\
\hline $03 / 06 / 2015$ & $\begin{array}{c}\mathrm{Rp} \\
2.983 .482\end{array}$ & $\begin{array}{c}\mathrm{Rp} \\
2.964 .082\end{array}$ & $\begin{array}{c}\mathrm{Rp} \\
19.400\end{array}$ & TURUN & TURUN & BERHASIL \\
\hline $04 / 06 / 2015$ & $\begin{array}{c}\mathrm{Rp} \\
2.972 .288\end{array}$ & $\begin{array}{c}\mathrm{Rp} \\
2.989 .711\end{array}$ & $\begin{array}{c}-\mathrm{Rp} \\
17.423\end{array}$ & NAIK & TURUN & GAGAL \\
\hline $05 / 06 / 2015$ & $\begin{array}{c}\mathrm{Rp} \\
2.993 .796 \\
\end{array}$ & $\begin{array}{c}\mathrm{Rp} \\
3.005 .567\end{array}$ & $\begin{array}{c}-\mathrm{Rp} \\
11.771\end{array}$ & NAIK & NAIK & BERHASIL \\
\hline
\end{tabular}

Tabel 2. Hasil Peramalan

C. Manajemen Basis Model

1. Diagram Use Case

Diagram Use Case digunakan untuk menggambarkan bagaimana user berinteraksi dengan sistem.

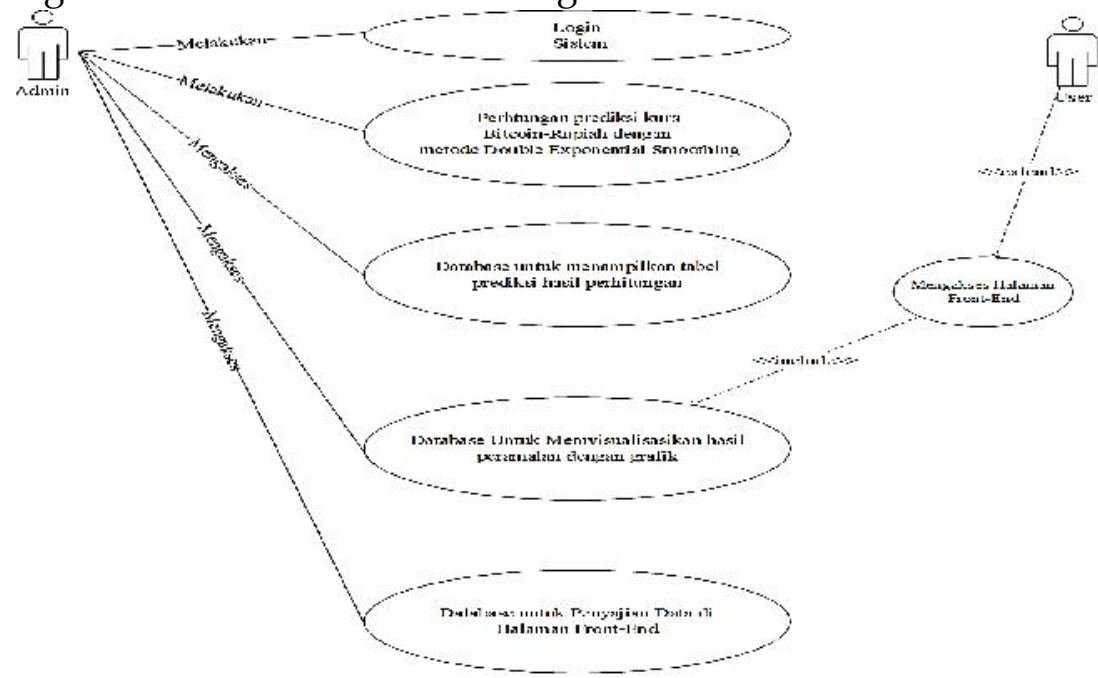

Gambar 1. Use Case Diagram 


\section{Activity Diagram}

Pada Activity diagram, akan dijelaskan aktifitas apa saja yang terjadi dalam proses sistem. Disini dijelaskan setiap aktfitas sistem dan user.

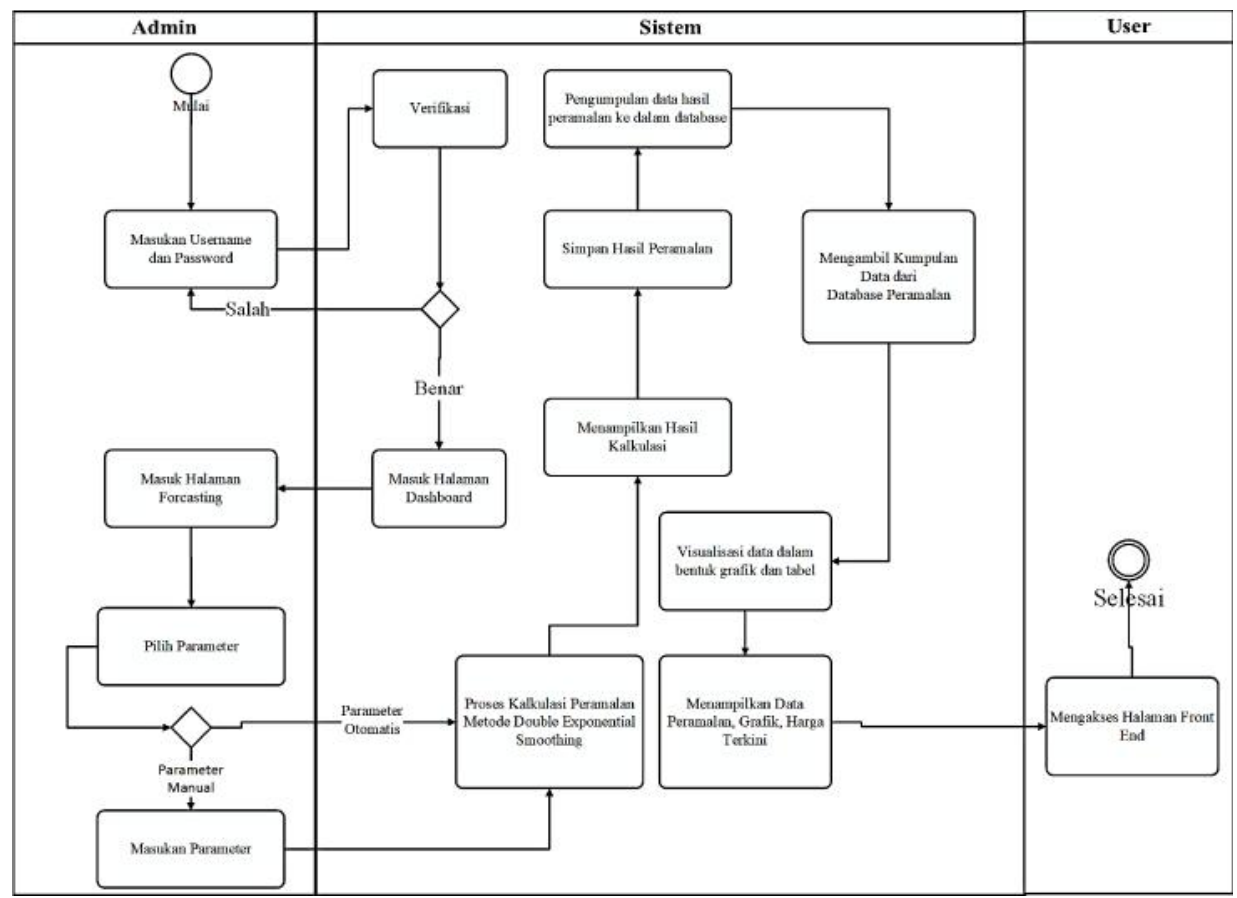

Gambar 2. Activity Diagram

D. Implementasi Sistem

1. Halaman Front And

Halaman Front End adalah halaman utama yang akan digunakan oleh masyarakat. Halaman ini akan diakses secara umum yang berisikan grafik, tabel historis dan informasi seputar Cryptocurrency. 


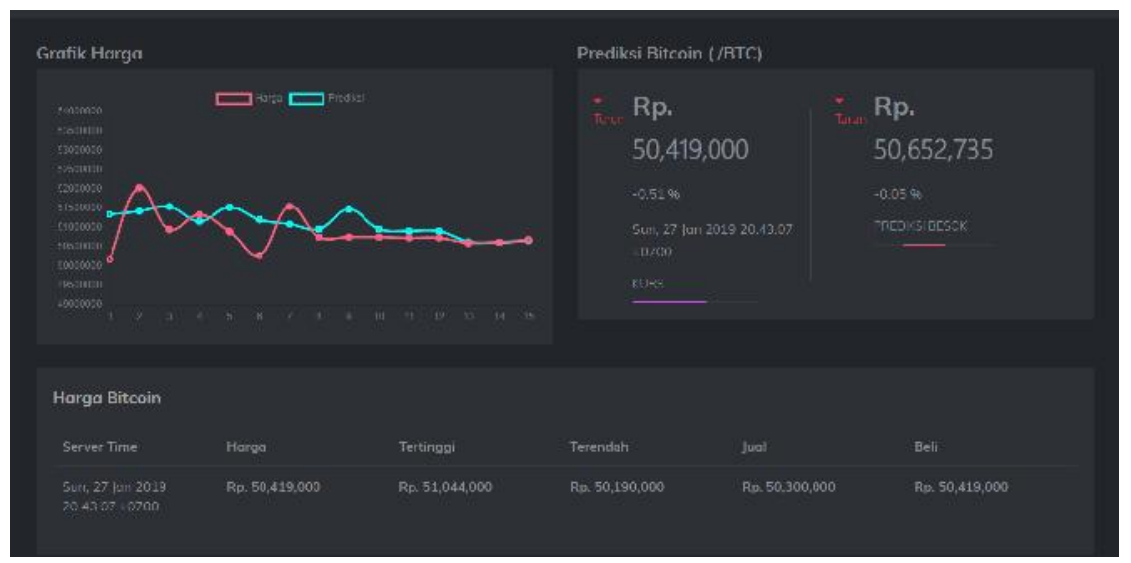

Gambar 3. Halaman Front-End

2. Halaman Dashboard Admin

Adalah halaman utama admin yang menampilkan ringkasan data peramalan dan kurs Bitcoin dari Database, dan visualisasi data.

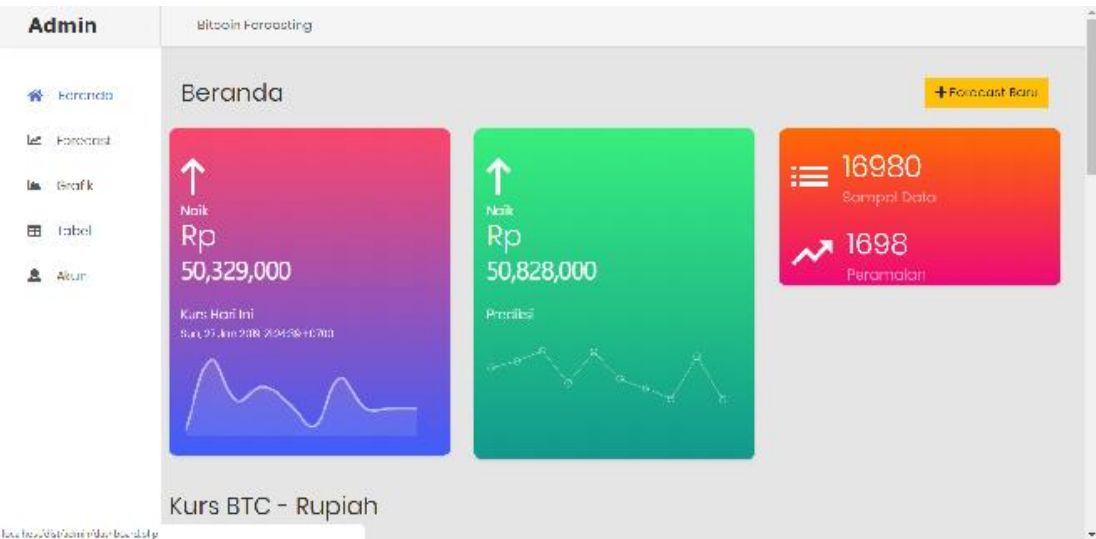

Gambar 4. Halaman Admin 


\section{Kesimpulan}

Aplikasi Prediksi Kurs Bitcoin-Rupiah di rancang menggunakan UML dan diterapkan dengan bahasa pemerograman web seperti PHP. Dan menggunakan HMTL. Aplikasi ini dirancang dengan memasukan sampel data yang didapat dari API Bitcoin kemduian dikalkulasikan dengan metode Double Exponential Smoothing. Hasil tersebut disimpan dalam database dan di Visualisasikan dengan menggunakan grafik dan tabel. 


\section{Daftar Pustaka}

Conway, J.. Beginners Guide to Cryptocurrencies, 1-10. 2014

Nakamoto, S. Bitcoin: A Peer-to Peer Electronic Cash System 2008.

Chaum, D. Blind Signatures for Untraceable Payments. Crypto. 1982

Dhika Khameswara,Tubagus dan Wido Hidayatullah. Bitcoin Uang Digital Masa Depan. 2014. Surya University

Lieberty,_Annastasya dan Radiant V. Imbar, Sistem Informasi Meramalkan Penjualan Barang Dengan Metode Double Exponential Smoothing (Studi kasus: PD. Padalarang Jaya). Jurnal Teknik Informatika dan Sistem Informasi Volume 1 Nomor 1 April 2015. 2015

Raihan, M. Syafwansyah Eff, dan Ahmad Hendrawan .Forcasting Model Exsponensial Smoothing Time Series Rata Rata Mechanical Availability Unit Off Highway Truck Cat 777d Caterpillar. Jurnal POROS TEKNIK Volume 8, No. 1, Juni 2016 :1-54 